\title{
Repoblamiento y recuperación del Centro Histórico de la ciudad de México, una acción pública híbrida, 2001-2006
}

\section{Repopulation and rescuing of Mexico City's historic centre; a hybrid public action, 2001-2006}

\author{
Víctor Manuel Delgadillo-Polanco*
}

\begin{abstract}
In this paper we analyse the urban, housing and rescuing policies related to the heritage of Mexico City's historic centre. We are interested in the policies that were carried out by the local government between 2001 and 2006 within the framework of a Latin American trend to return to central urban areas. We address the context in which this return to the centre has been consolidated, as well as the renewed interest for rescuing historic city centres. There is evidence of a differentiated public action that grants a higher status to the private sector compared to that of the resident population and the city itself. This goes beyond a neutral discourse about public interests and the rescue of humankind heritage. This paper is the result of a doctoral research together with current efforts to evaluate the impact of public policies in the so-called central city.
\end{abstract}

Keywords: central urban areas, historic centre, urban heritage rescuing.

\section{Resumen}

En este artículo se analizan las políticas urbanas, habitacionales y de recuperación del patrimonio en el Centro Histórico de la ciudad de México realizadas por el gobierno local entre 2001 y 2006 en el marco de una tendencia latinoamericana de retorno a las áreas urbanas centrales. Se aborda el contexto en que se ha consolidado el retorno al centro de las ciudades y el renovado interés por recuperar los centros históricos. Asimismo, se evidencia una acción pública diferenciada que privilegia al sector privado por encima de la población residente y la ciudad, más allá de un discurso neutro que habla del interés público y del rescate del patrimonio de la humanidad. El artículo es resultado de una investigación doctoral y otra en curso, que evalúa los impactos de las políticas públicas en la llamada ciudad central.

Palabras clave: áreas urbanas centrales, centro histórico, recuperación del patrimonio urbano.

* Colegio de Humanidades y Ciencias Sociales de la Universidad Autónoma de la Ciudad de México, Plantel San Lorenzo Tezonco. Correo-e: victor_delgadill@hotmail.com. 


\section{Introducción}

Después de décadas de expansión urbana y crecimiento demográfico exponenciales, en muchas de las grandes ciudades latinoamericanas se realiza una serie de iniciativas cuyo objetivo es revalorar y regresar a las antiguas áreas urbanas centrales. Se trata de un conjunto de esfuerzos que con distintos intereses y propósitos (la recuperación del patrimonio histórico, el reciclaje urbano, la vivienda, el comercio o los servicios) pretenden: 1) revertir las tendencias de crecimiento urbano expansivo, de abandono y deterioro de las áreas centrales y proteger las áreas verdes periféricas; o bien, 2) hacer negocios inmobiliarios y turísticos o acciones altruistas y de marketing político, que tienen como fundamento el aprovechamiento y reapropiación del rico legado urbano arquitectónico que caracteriza a las antiguas zonas centrales. Estos esfuerzos se realizan en el marco de nuevos escenarios urbanos y demográficos que indican que el proceso de migración campo-ciudad ha concluido, que las tasas de crecimiento demográfico tienden a disminuir y que las ciudades del siglo XXI desempeñan el doble papel de motor de la economía globalizada y esperanza de vida de la población mundial.

El nuevo regreso a (una parte de) el centro ${ }^{1}$ es una tendencia que se ha generalizado en las ciudades de los países más desarrollados desde la década de 1970, y recientemente de forma fragmentada y puntual -pero creciente- se ha venido consolidando en América Latina, tanto en el debate académico como en la agenda pública, hasta constituirse en los albores del siglo XXI en un paradigma del debate urbano y de las políticas urbanísticas latinoamericanas. La incursión del sector privado en estas áreas urbanas es escaso y mucho más reciente. Además, a diferencia de las ciudades europeas, las iniciativas en nuestra región normalmente han estado motivadas por la recuperación de los monumentos y no por la problemática social que subyace en esos territorios: el hábitat deteriorado ocupado densamente por población pobre.

El presente artículo aborda el contexto (demográfico, urbano y económico) latinoamericano en que se ha fraguado el retorno al centro, evidencia las grandes desigualdades sociales y espacia-

${ }^{1}$ El retorno al centro no es un tema tan nuevo. En el transcurso del siglo xx se efectuaron diversos proyectos para mantener, mejorar o renovar el funcionamiento del centro de la ciudad. En este sentido, este proceso se puede interpretar como un cíclico retorno al centro bajo distintas concepciones, necesidades y paradigmas. 
les que históricamente han caracterizado estos territorios y presenta las políticas urbanas, habitacionales y de recuperación del patrimonio que se han desplegado en las áreas centrales de la ciudad de México entre 2001 y 2006. El artículo trata de evidenciar quiénes han sido los protagonistas y beneficiarios directos de tales políticas, más allá del discurso del bien común, del privilegio a la población más humilde y de la recuperación del Patrimonio de la Humanidad.

Los resultados que aquí se presentan son producto de una investigación sobre la vivienda popular en los centros históricos de Buenos Aires, ciudad de México y Quito, realizada en el Programa de Doctorado en Urbanismo de la Universidad Nacional Autónoma de México, así como de una investigación en curso que analiza las recientes políticas urbanas en el centro de la ciudad de México.

\section{El contexto}

\subsection{Nuevos escenarios urbanos y demográficos}

Latinoamérica es una región en proceso de transición demográfica. Por un lado, alcanza en promedio una tasa de urbanización (población que habita en ciudades) de 75.4\% (un Habitat, 2003), similar a la de los países más desarrollados. En el 2000 México alcanzaba $74.4 \%$ y varios países del Cono Sur tenían tasas superiores a $80 \%$. Por otro lado, las tasas de crecimiento demográfico tienden a disminuir, particularmente en las grandes ciudades (la urbanización se considera un factor importante que contribuye a ello). En América Latina las tasas de crecimiento demográfico han disminuido considerablemente del tercer al último cuarto del siglo xx de 2.6 a 1.9. Evidentemente, estos promedios esconden una gran heterogeneidad de situaciones en la región: los países del Cono Sur y Cuba han alcanzado tasas de crecimiento demográfico inferiores a la media regional.

Alfredo Lattes (2001) consigna una serie de cambios demográficos en los sistemas urbanos de América Latina: la población urbana se está desconcentrando de las ciudades mayores (las metrópolis crecen poco e incluso pierden población en las áreas centrales); las ciudades medias crecen a ritmos mayores; la migración campo-ciudad ha disminuido su peso en el crecimiento urbano, mientras que la migración internacional adquiere una gran relevancia. 
En conjunto, estos datos indicarían que arribamos al fin de la migración del campo a la ciudad y que pasó el periodo de crecimiento urbano incontenible y de gran demanda de empleo, vivienda y servicios. Para Ricardo Jordán transitamos de la "urbanización sin fin, al fin de la urbanización” (2003: 52). Sin embargo, otros autores como Meter Nintied (1998) advierten que la migración del campo a la ciudad continuará, sobre todo en países con menores niveles de urbanización, debido a que la reducción de las barreras comerciales y la creciente productividad en la agricultura requerirá de menos trabajadores agrícolas.

Además, vale reconocer que, por un lado, la presión sobre las ciudades, la vivienda, el empleo y los servicios continúa existiendo, pues la población sigue creciendo en términos absolutos y cada día se forman nuevos hogares producto de décadas de explosión demográfica; $y$, por otro, la transición demográfica se acompaña tanto del incremento de migración internacional de los países en desarrollo hacia los del primer mundo (a distancias cada vez más lejanas del lugar de origen), ${ }^{2}$ así como del incremento de la pobreza urbana. Según Naciones Unidas (UN Habitat, 2003), 924 millones de personas (120 de ellos en América Latina y el Caribe), de un total de seis billones de habitantes del planeta, vivían en tugurios $^{3}$ en el año 2000 y, de acuerdo con la misma fuente, esta población se duplicará en 30 años.

Así, una primera y evidente conclusión es que la urbanización del mundo, más allá de sus ventajas o desventajas, es un hecho irreversible. La población se muda a las ciudades porque allí encuentra posibilidades de reproducción y futuro, por lo que éstas constituyen la esperanza de vida de la población mundial, mientras que la agenda de los gobiernos se define en función de las ciudades y las demandas de la población urbana.

\subsection{La globalización y el nuevo papel de las ciudades}

La globalización de la economía ha implicado una gran transformación en las grandes ciudades y metrópolis latinoamericanas,

2 El impacto de la migración sobre el desarrollo se estima positivo en los países receptores y expulsores, los primeros incrementan sus ganancias con mano de obra barata y sin derechos laborales y en los segundos funciona como válvula de escape para el desempleo, además de que las remesas que los migrantes envían constituyen un importante ingreso de recursos económicos.

${ }^{3} \mathrm{La}$ ONU tiene una definición operacional de tugurio que abarca una amplia forma de alojamiento para población de bajos ingresos y combina factores físicos y sociales: hacinamiento, pobre calidad de la vivienda, inseguridad en la tenencia del alojamiento, acceso inadecuado a servicios, etcétera. 
muchas de ellas han sufrido procesos de desindustrialización y de terciarización en su base económica, lo que implica el abandono y obsolescencia de zonas fabriles, la multiplicación de las actividades terciarias, el desplazamiento de la función habitacional en áreas urbanas centrales, la modernización selectiva del territorio, la aparición de nuevas centralidades, la fragmentación urbana, etcétera.

Las políticas económicas neoliberales no han tenido éxito en la recuperación económica de los países latinoamericanos, pero han producido la bancarrota de varias actividades industriales y productivas, han profundizado las desigualdades sociales e incrementado el número de pobres (muchos de los cuales se concentran en las ciudades), ${ }^{4}$ han reducido al mínimo las políticas sociales, han precarizado el empleo y han privatizado varias atribuciones públicas con el argumento de la ausencia de recursos financieros, la ineficiencia, la burocracia y la corrupción del Estado. Según la CEPAL (datos citados por Jordán, 2003: 52), en el año 2000 el 50\% de los trabajadores urbanos en América Latina se ocupaban en el sector informal. De acuerdo con el reporte mundial sobre asentamientos humanos 2003 de la onU, "las políticas de reajuste económico [...] han reducido los empleos e incrementado la inequidad, lo que ha empeorado las condiciones de vida de la población y ha incrementado el número de tugurios" (UN Habitat, 2003: 27) y de pobres. Así, una parte de varias ciudades, en particular las áreas centrales, se han transformado en reductos de pobreza donde cientos de familias de muy escasos ingresos, indigentes y grupos vulnerables encuentran posibilidades de sobrevivencia; y en centros de comercio informal en escala regional que invaden la vía pública y ofertan todo tipo de productos baratos para la población de bajos ingresos.

Asimismo, en la región -y de forma similar a los antiguos centros fabriles del primer mundo- se ha acelerado la declinación de las grandes ciudades como centros de producción industrial, mientras que las actividades terciarias formales e informales han pasado a ser dominantes en la estructura económica respectiva. $\mathrm{Al}$ proceso de desindustrialización relativa han contribuido tanto la creciente normatividad en materia ambiental, el encarecimiento de las condiciones de producción y la competencia inter-

\footnotetext{
${ }^{4}$ Richard Batley señala que la nueva economía mundial no explica las tremendas desigualdades socioeconómicas de América Latina, pues tanto las regiones menos vinculadas a la globalización (países del África al sur del Sahara) como las más vinculadas (Europa y Asia central) "presentan mucho menos desigualdades" (1998: 15).
} 
nacional. Los dos primeros factores obligaron a las industrias a tomar medidas de prevención de la contaminación y/o al desplazamiento de muchas de ellas, para las que resultó más económico trasladarse a las periferias o a otras ciudades. En el último caso se trata de la bancarrota de numerosas industrias que no pueden competir contra bienes producidos en regiones donde la mano de obra es baratísima. Conviene señalar que el proceso de desindustrialización en las grandes ciudades latinoamericanas no es total, pues se mantiene un parque industrial importante. En este mismo sentido se debe enfatizar que globalización no es sinónimo de desindustrialización y que la industria continúa siendo una importante base material de la riqueza de los países, otra cosa es que sus patrones de ubicación espacial se encuentren fragmentados y dispersos en varias regiones del mundo.

Además, las ciudades y en particular las grandes metrópolis actualmente desempeñan un papel preponderante en la economía nacional y mundial. No es casual que se les asigne el papel de motor del desarrollo en una economía mundial cada vez más interconectada. De acuerdo con el Banco Mundial, las zonas urbanas de los países con ingresos bajos y medios generan entre 55\% y 73\% del producto nacional bruto (datos citados por Jordán, 2003: 47), mientras que las grandes capitales latinoamericanas -a pesar de su desindustrialización- continúan generando o facturando una importante proporción del producto interno bruto nacional. Por ejemplo, en el 2000 Buenos Aires contribuía con $25 \%$ del PIB argentino, mientras que la capital mexicana lo hacía con 22\% del PIB nacional (datos citados en Delgadillo, 2005).

El nuevo rol de las ciudades: el creciente proceso de globalización de la economía, favorecido por las nuevas tecnologías de telecomunicación, no ha implicado el declive de la ciudad en un momento en que las funciones de gestión y control de la economía mundial se pueden desarrollar de forma virtual desde cualquier punto del planeta. Algunos autores advierten sobre la desaparición de la ciudad a través del fenómeno de la urbanización difusa y la telépolis ${ }^{5}$ producida por el trabajo a distancia facilitado por las nuevas tecnologías de la comunicación; o bien, sobre la pérdida del espacio público y del espacio real, en favor del virtual. Sin embargo, los hechos y diversos autores señalan lo contrario. La globalización asigna a las ciudades nuevas funcio-

${ }_{5}^{5}$ Carlos García (2004) añadiría el repertorio de la ciudad hojaldre: la ciberciudad, la E-topia, la Dis-Topia, la ciudad chip, la Edge city o ciudad frontera, etcétera. 
nes: el papel de motor del desarrollo y de coordinación y gestión de la economía mundial. Saskia Sassen (1997) diría que las ciudades son el sistema nervioso de la economía global.

Por último, vale recordar que una característica de la globalización de la economía es su carácter excluyente tanto en el ámbito mundial como al interior de las ciudades. Así, algunas regiones y ciudades no se articulan al mercado mundial o lo hacen en condiciones desfavorables, mientras que en escala intraurbana los procesos de modernización y mejoramiento actúan sólo en pequeñas partes de la ciudad e incluso pequeñas partes de los llamados centros históricos.

\subsection{El agotamiento del patrón de urbanización periférica}

La expansión urbana periférica y el vaciamiento y abandono de las áreas urbanas centrales, que han caracterizado las tendencias de desarrollo urbano de muchas ciudades latinoamericanas, han generado diversas consecuencias negativas para los habitantes y las ciudades en su conjunto: despoblamiento y deterioro de las áreas centrales con el consecuente desperdicio o subutilización de los servicios, infraestructura y equipamiento social acumulados; altos costos en la extensión de redes de servicios e infraestructura y de transporte hasta periferias cada vez más alejadas; deterioro del medio ambiente; así como pérdida de áreas agrícolas, forestales y otros recursos naturales.

Sin embargo, la expansión urbana periférica no se detiene porque continúa aportando beneficios a los gobiernos, los inversionistas y la población de bajos y altos ingresos. En efecto, esta forma de urbanización no es un proceso natural sino producido por el mercado inmobiliario. Por tratarse generalmente de un suelo barato se pueden adquirir grandes extensiones; no hay tantos propietarios ni tanta irregularidad jurídica en la propiedad del suelo como en las áreas centrales; el gobierno edifica vivienda social, los desarrolladores grandes conjuntos habitacionales, los ricos construyen mansiones en grandes terrenos y los pobres adquieren pequeños lotes sin servicios a precios accesibles (Rojas et al., 2004). No obstante, vale reiterar que esta forma de crecimiento urbano tiene muchos inconvenientes: devasta el medio ambiente, incrementa la distancia de la vivienda al empleo, aleja a la población de los servicios y equipamientos, y -si se contabilizarán los verdaderos costos- la urbanización periférica es más cara que la reutilización de las áreas centrales subu- 
tilizadas o abandonadas. Por ejemplo, en Santiago de Chile el costo estimado de la urbanización periférica es 11 veces más que la reutilización del centro de la ciudad (Aravena, 2005).

Por su parte, las áreas urbanas centrales y los centros históricos pierden población y vivienda, fenómeno que se genera por la combinación de varias causas: desplazamiento de la función habitacional por actividades más lucrativas (oficinas y comercios), deterioro edilicio y urbano, encarecimiento de las condiciones de vida, así como de los programas de rescate de los centros históricos. En efecto, entre 1990 y 2000, en una década en que se realizaron muchos programas de recuperación del patrimonio histórico: el centro histórico de Quito perdió 31.4\% de su población, el de Buenos Aires 20\%, la comuna de Santiago 17\% y el de la ciudad de México 14\%; mientras el centro histórico de la ciudad de Puebla perdió $19.6 \%$ de sus habitantes entre 1992 y 1995 (Delgadillo, 2005). Sin embargo, a menudo las zonas metropolitanas que contienen estos territorios centrales crecen en expansión física y en población.

Así, en la discusión aparecen dos modelos opuestos de urbanización: la ciudad compacta, tema de debate en las ciudades europeas (Wentz, 2000) versus la ciudad extendida, o bien, la vuelta a la ciudad construida (Carrión, 2001) versus el expansionismo urbano periférico. El primero contribuye a un desarrollo urbano racional y sostenible, en tanto que el segundo es un modelo depredador del medio ambiente y despilfarrador de la ciudad construida, además de que es una expresión de la pobreza social urbana, de un desarrollo urbano liderado por el mercado inmobiliario y de un gobierno fragmentado (particularmente en las zonas metropolitanas) que, incapaz de actuar, asiste como espectador a la expansión de la ciudad.

En este renovado interés por recuperar las áreas urbanas centrales, Rojas et al. (2004) incluyen las áreas infrautilizadas o abandonadas, áreas deterioradas, así como la infraestructura fabril y de comunicaciones abandonada u obsoleta debido a los cambios tecnológicos y transformaciones en los sistemas de producción y en los medios de transporte.

\subsection{La modernización selectiva del territorio}

En las últimas dos décadas, en varias ciudades latinoamericanas se han efectuado procesos de reestructuración urbana a través de proyectos de gran dimensión en términos de capital, superfi- 
cie, tecnología y diseño que han conformado una nueva geografía de centralidades múltiples y han obligado a una redefinición del papel que desempeña el centro histórico en el conjunto de la ciudad. Se trata de un proceso de modernización selectiva del territorio que se apoya en el paradigma de la planeación estratégica, actúa en las áreas urbanas más rentables y contribuye a la fragmentación de la ciudad y a incrementar procesos de segregación socioespacial. En estos proyectos el Estado realiza las obras de infraestructura y servicios para atraer al sector privado local y/o extranjero.

- Desde fines de la década de 1980, en Buenos Aires se han realizado importantes proyectos viales, el reciclaje de hitos urbanos (El Abasto con inversión de George Soros), la renovación del antiguo Puerto Madero y los programas de rescate del casco histórico y de la Avenida de Mayo.

- En la ciudad de México las transformaciones espaciales desde principios de la década de 1990 se distribuyen en la ciudad central y se extienden selectivamente por el poniente a lo largo de corredores urbanos que articulan el ámbito metropolitano. Las intervenciones más recientes se han realizado en Santa Fe (de acuerdo con varios autores, éste es un enclave vinculado directamente con el proceso de globalización), el Paseo de la Reforma (la Torre Mayor con inversión del corporativo Reichmann), La Alameda y el Centro Histórico, donde Carlos Slim -el inversionista más rico de América Latina- adquirió alrededor de 65 inmuebles a partir de 2002 .

Para Marcelo Balbó (2003) las transformaciones urbanas que desde la década de 1990 se realizan en las ciudades latinoamericanas promueven la generación de una ciudad excluyente y exclusiva para la población de elevados ingresos, el turismo y la inversión internacional. Esta población tiende cada vez más a aislarse y a construir una ciudad propia hecha de partes localizadas en diversos territorios con acceso reservado, que se vinculan a través de vías urbanas o metropolitanas construidas con costosas inversiones. Esta lógica de la ciudad por partes a nivel urbano y arquitectónico busca una distinción explícita con la ciudad existente y reproduce, de manera más profunda, la segregación social y espacial del territorio. Por su parte, Sergio Tamayo (2001) señala que la ciudad de México en la década de 1990 sufrió grandes 
cambios: la centralidad urbana se expandió a lo largo de ejes metropolitanos en el centro y poniente de la ciudad. Se trata de pedazos de ciudad o archipiélagos con o sin conexión entre sí, donde la arquitectura monumental en vez de construir ciudad ha contribuido a forjar un territorio "fragmentado, selectivo, individualizado y a veces groseramente polarizado" (Tamayo, 2001: 190). Como se verá adelante, la actuación selectiva en el territorio alcanza a los centros históricos, donde se recuperan o intervienen los enclaves más interesantes para el sector público y recientemente también para el privado.

\subsection{El renovado interés por el rescate de centros históricos}

En las últimas tres décadas, y particularmente en la última, en América Latina se generalizaron los programas de recuperación de (una parte de) los centros históricos, con grandes inversiones públicas y con contribuciones importantes del sector privado bajo inéditas formas de gestión público-privadas, en general en beneficio de las segundas. Estas iniciativas corresponden a un renovado y creciente interés por conservar cada vez más un mayor número de objetos patrimoniales producidos en umbrales de tiempo cada vez más cercanos. Tales esfuerzos han transitado desde la promulgación de legislaciones y de la restauración puntual de monumentos, hasta la realización de programas de rehabilitación urbana de algunos territorios.

En una investigación recientemente concluida (Delgadillo, 2005) que explora el futuro de la vivienda tugurizada en los centros históricos de Buenos Aires, Quito y la ciudad de México, se evidencian claramente los propósitos de los programas de recuperación del patrimonio urbano arquitectónico impulsados por los gobiernos nacionales y locales con cuantiosos recursos públicos, más allá de un discurso neutro que dice salvaguardar el patrimonio nacional y de la humanidad. Cuatro son los grandes rasgos que caracterizan los programas recientes de rescate de estos centros históricos:

1. La concentración de grandes inversiones públicas a fondo perdido en las zonas más interesantes, rentables y factibles para los sectores público y privado.

2. El uso del discurso del beneficio de toda la sociedad y del interés público, cuando directamente se favorece al sector 
privado (propietarios, desarrolladores inmobiliarios, promotores del turismo, etcétera).

3. Los beneficios y la plusvalía son apropiados por los particulares y la decisión de reinvertir en esos territorios depende de ellos.

4. La ausencia de inversiones en los barrios deteriorados, tugurizados y densamente habitados por pobres, que también contienen un rico patrimonio edilicio. Además, los damnificados directos de estos programas son las actividades populares que atentan contra la dignidad del patrimonio (por ejemplo, la celebración de Reyes Magos en la Alameda de la ciudad de México) y el comercio informal en la vía pública.

El resultado de esta lógica de actuación es la profundización de las diferencias entre una zona que se rescata y otra que permanece al margen de inversiones que reviertan el deterioro y el caos urbano, y entre inversionistas que gozan de expectativas positivas para recuperar el patrimonio y asegurar su negocio, $\mathrm{y}$ residentes de bajos ingresos quienes en el mejor de los casos reciben significativas ayudas para mejorar sus condiciones de vida, valorar su patrimonio y algunos créditos parar adquirir o mejorar su vivienda.

Desde la teoría, uno de los principales avances en materia de protección del patrimonio urbano arquitectónico es la perspectiva que reconoce a los centros históricos no como un conjunto de piezas del pasado, sino como vigorosos y vitales espacios urbanos que pueden aportar mucho para la construcción de la ciudad del futuro (FCH, 2001; Herzog, 2006; Mercado, 1997; Tung, 2002). Aquí aparece la calidad, vitalidad y posibilidades de uso del espacio público; la escala humana de la ciudad histórica; la diversidad cultural y socioeconómica de usuarios y residentes; así como el principio de mezcla social, funcional y de financiamiento, lo que no implica revolver a los diversos grupos socioeconómicos. Bajo este enfoque, los centros históricos y el espacio público no se conciben como islas sino como espacios conformados en un proceso histórico, social y político en el transcurso del tiempo y como una parte muy importante de la ciudad que expresa problemas y dinámicas socioeconómicas y políticas que se 
generan en ámbitos geográficos y en dinámicas socioeconómicas mucho más amplias.

\subsection{Competencia entre ciudades y centros históricos}

En la competencia mundial que se da entre las ciudades por atraer capitales foráneos, los centros históricos se han convertido en un valor adicional que se suma a las capacidades y fortalezas de cada ciudad. Si varias ciudades pueden ofrecer al capital internacional condiciones de inversión similares: infraestructura, instalaciones fabriles, servicios financieros y de comunicaciones, mano de obra barata, recursos humanos altamente calificados y un mercado cautivo constituido por miles o millones de personas, los barrios antiguos aparecen como un objeto único que posee valor histórico y cultural, accesibilidad y atributos suficientes para incrementar el interés sobre esa ciudad. El marketing pretende atraer inversionistas y colocar en una mejor posición a los centros históricos, pero también obtener dividendos políticos que evidentemente no se logran de manera mecánica.

La idea de obtener provecho político y económico de las transformaciones urbanas y financiar los proyectos urbanos no es una característica de la globalización y tampoco es nueva. Giandomenico Amendola (2000) recuerda que la tarjeta postal es el más antiguo y menospreciado de los instrumentos de marketing urbano, pero que en el contexto de la globalización la venta de la imagen de la ciudad es una empresa que adquiere otra dimensión, pues los capitales y las personas están menos vinculados al territorio que en el pasado. Así, cada ciudad debe encontrar una imagen estratégica para atraer inversiones, empresas y personas y presentarla como la mejor posible para vivir, producir y competir; se trata de convencer para atraer y de seducir para que la gente y la inversión se queden o vuelvan. El riesgo es que para vencer la competencia se adecue la ciudad a las necesidades del mercado (inversionistas y turistas) y no para la población residente. En el caso latinoamericano los esfuerzos son dobles: antes de vender la imagen hay que limpiarla y garantizar la seguridad para las visitas, lo que incluye eliminar la fuerte presencia del comercio en la vía pública y la delincuencia a través de programas de reordenamiento del comercio informal y de toda una parafernalia de seguridad. 


\section{7. ¿Globalización o marketing político?}

En América Latina los esfuerzos de recuperación de los centros históricos parecen tener más vínculos con procesos de marketing político que propiamente con el proceso de la globalización de la economía. La incorporación del sector privado a estos procesos de reconquista de las áreas urbanas centrales en América Latina, a diferencia de las ciudades europeas y norteamericanas, es apenas incipiente. En el caso mexicano, Patrice Melé (1998) ha demostrado la activa participación del Estado, en sus diversos niveles de gobierno, en las profundas transformaciones de sus centros históricos efectuadas en las dos últimas décadas. Allí están el Centro de Convenciones en el barrio de San Francisco del Centro Histórico de la ciudad de Puebla, la Macroplaza de Monterrey, la Plaza Tapatía en Guadalajara, el programa Échame una Manita (1991-1994) y el reciente programa (2002-2006) de recuperación del Centro Histórico de la ciudad de México, así como el remozamiento de otros tantos centros históricos de provincia. Melé señala que si este conjunto de intervenciones no resolvió los problemas de deterioro, tráfico, comercio ambulante e inseguridad, sí contribuyó a la construcción de una nueva representación colectiva de esos espacios como lugares de identidad.

\section{Las nuevas políticas urbanas y de recuperación del patrimonio histórico en la ciudad de México}

\section{1. ¿Una política sin planificación?}

Entre 2001 y 2006 el Gobierno del Distrito Federal (GDF) realizó un conjunto de políticas urbanas, habitacionales y de recuperación del patrimonio histórico que se aplicaron a las áreas urbanas centrales. Por un lado, una pragmática política de desarrollo urbano promovió la construcción de vivienda en las cuatro delegaciones centrales y la restringió en el resto del territorio, asimismo, se ejecutó una ambiciosa política de vivienda que se propuso realizar 150 mil acciones habitacionales en el sexenio para la población de bajos ingresos. Por otro lado, en momentos diferentes se iniciaron dos programas de recuperación del patrimonio urbano arquitectónico: a partir de 2001 el remozamiento del Paseo de la Reforma, como parte de la política de turismo, y a partir de 2002 la nueva recuperación del Centro Histórico, que 
acompaña al interés del inversionista más grande del país por rescatar ese territorio.

Tales programas se enmarcaban en una política más general de austeridad que repetía atender primero a los pobres, pero que en los hechos también otorgó privilegios a algunos inversionistas, a clases medias y a la Iglesia católica (religión mayoritaria pero no única en el país). En el primer caso se trata de los programas sociales que otorgan ayudas económicas a adultos mayores, a personas con discapacidad, a niñas y niños en situación de vulnerabilidad, desayunos escolares, reparto de leche, mantenimiento de unidades habitacionales, así como créditos para el acceso o mejoramiento de una vivienda; y en el segundo caso, se pueden incluir los programas de rescate del Centro Histórico y del Paseo de la Reforma, la Plaza Mariana y los segundos pisos a las principales vialidades de la ciudad, en donde los recursos públicos se invierten a fondo perdido en beneficio de propietarios, inversionistas inmobiliarios, clero católico y usuarios de transporte privado.

Además, las políticas de desarrollo urbano, vivienda y rescate del patrimonio histórico que actúan en las áreas centrales no tienen vínculos entre sí (salvo retóricos), a menudo son contradictorias y no se trata de acciones planeadas en el marco de un proyecto consensado de ciudad (por lo menos en el año 2001), sino fruto de la voluntad política del Ejecutivo local. Por ello, conviene analizar cada política y programa por separado, pues cada una tiene su propia lógica de financiamiento y actuación, así como su población y territorios objetivos.

\subsection{Una política restrictiva de desarrollo urbano, el Bando $\mathrm{N}^{\circ} 2$}

En diciembre de 2000, a través de un instrumento informativo, el Bando $N^{\circ} 2$, se dieron a conocer las directrices de la política de desarrollo urbano del segundo gobierno democrático del Distrito Federal que limitaban la construcción de unidades habitacionales (mayores de 35 viviendas) y desarrollos comerciales en las cuatro delegaciones centrales. ${ }^{6}$

\footnotetext{
${ }^{6}$ Este Bando restringía expresamente el crecimiento de la ciudad en nueve delegaciones (Álvaro Obregón, Coyoacán, Cuajimalpa, Iztapalapa, Magdalena Contreras, Milpa Alta, Tláhuac, Tlalpan y Xochimilco), señalaba que promovería el crecimiento de población en las cuatro delegaciones centrales (Benito Juárez, Cuauhtémoc, Miguel Hidalgo y Venustiano Carranza), pero omitía cualquier referencia a las tres delegaciones restantes (Azcapotzalco, G. A. Madero e Iztacalco).
} 
La preocupación, expresada en el Bando de forma contundente, de revertir el crecimiento desordenado de la ciudad, la pérdida de población, el vaciamiento de las áreas centrales y la urbanización del suelo de conservación ecológica la comparten académicos, gobiernos, intelectuales, funcionarios y otros actores sociales, pero las discrepancias y críticas se hicieron por la forma pragmática en que se pretendían alcanzar tales propósitos.

- El Bando no fue producto de un proyecto consensado de ciudad ni tenía sustento en el marco jurídico. ${ }^{7}$ Adquirió estatus legal hasta el año 2003 a través de su inclusión en el Programa General de Desarrollo Urbano del Distrito Federal (PGDUDF).

- El argumento sobre el despoblamiento de la ciudad central es endeble, pues aunque ésta perdió 1.2 millones de habitantes en 30 años, en el año 2000 eran ocho y no sólo cuatro las delegaciones que perdían población. Además, este mismo proceso de pérdida de población se presenta en la cabecera de otras delegaciones, como Xochimilco.

- El concepto de ciudad central confunde la centralidad urbana (un atributo funcional) con un atributo geográfico que se aplica a cuatro demarcaciones políticas y no corresponde con una ciudad de 18 millones de habitantes, integrada por un sistema de centralidades múltiples alojadas en centros, subcentros, nodos y corredores urbanos.

- No se previó la creación de reservas territoriales para la edificación de vivienda social, lo que provocó el incremento del precio del suelo. Así, por ejemplo, la población derechohabiente del Instituto del Fondo Nacional de Vivienda para los Trabajadores (Infonavit) en el D. F. satisface su necesidad de vivienda en los municipios vecinos, donde el suelo es más barato. El Coordinador Regional de la Zona Metropolitana del Infonavit señaló claramente que de 26,853 créditos otorgados por este instituto a sus derechohabientes en el D. F. en el año 2004, 75\% se ejerció en el Estado de México (Morteo Báez, 2005). Así, esta política urbana restrictiva provocó a su manera la expansión urbana periférica de la Zona Metropolitana, donde la po-

\footnotetext{
${ }^{7}$ El marco legal respectivo se integra por la Ley de Desarrollo Urbano y su Reglamento, y por los Programas de Desarrollo Urbano (uno general del D. F, 16 delegacionales y otros tantos parciales). Ningun programa prohibía la construcción de vivienda en las delegaciones aludidas por el Bando $N^{\circ} 2$.
} 
blación de menores ingresos encuentra suelo y vivienda accesible a sus ingresos.

La construcción de vivienda en la ciudad central por el sector privado: los desarrolladores inmobiliarios, que inicialmente se quejaban de las restricciones a la construcción de vivienda en las delegaciones periféricas y por el encarecimiento del suelo en las delegaciones centrales, parecen haber encontrado un nicho de mercado que les permitió realizar un buen negocio inmobiliario. De acuerdo con la Secretaría de Desarrollo Urbano y Vivienda (Seduvi, 2006), hasta septiembre de 2006 se habían otorgado 149 mil certificados de factibilidad de (construcción de) vivienda en todo el D. F., 116 mil viviendas en las cuatro delegaciones centrales y 3,885 en el Centro Histórico. Evidentemente, no todas estas viviendas se construyen, sin embargo, las instituciones públicas generalmente deducen resultados favorables a partir de estos trámites burocráticos. Por ejemplo, a partir de un registro de licencias y manifestaciones de construcción, la Procuraduría Ambiental y del Ordenamiento del Territorio del D. F. (РAOT, 2006) dijo que de 2000 a 2004 habrían llegado a la ciudad central cien mil nuevos habitantes, mientras que la titular de la Seduvi señaló en septiembre de 2005 que, gracias a la política habitacional y de desarrollo urbano, la ciudad central habría ganado 196,450 habitantes nuevos (Castillo, 2005). ${ }^{8}$ Así, se infiere un caudal enorme de nuevos habitantes, como si todas las viviendas estuvieran ocupadas por gente que viene de fuera, como si hubieran sido construidas para población de medianos o bajos ingresos y como si tuvieran la misma composición familiar.

Las zonas donde el sector privado ha producido una mayor oferta de vivienda para estratos socioeconómicos medios y altos son las colonias con mejor infraestructura, servicios, áreas verdes y espacios públicos. Los beneficiarios son personas que pueden pagar un suelo encarecido (debido a la política del Bando 2). Vale añadir que la edificación de nuevos conjuntos habitacionales ha estado acompañada de protestas e inconformidad de vecinos de algunas colonias. Las quejas de la población residente son en tres sentidos: el impacto de la llegada de nuevos vecinos en términos de la capacidad de la infraestructura y los servicios, el no respeto a la normatividad urbana y de edificación por parte

${ }^{8}$ Los cálculos provienen de considerar que se construyó 80\% de 109,470 viviendas dictaminadas como factibles para el área central, y que éstas las habitan 3.5 personas cada una. 
de las empresas constructoras, los malestares que causan las obras mismas, así como la obstrucción de las vías de circulación.

\subsection{Una ambiciosa política de (financiamiento de) vivienda}

Los compromisos y metas de la política habitacional se plasmaron en dos documentos: a) el Bando informativo $N^{\circ} 2$, comentado antes, señala que se impulsaría en las delegaciones centrales un programa de construcción de vivienda para la gente humilde de la ciudad; y b) el Acuerdo sobre Politica Habitacional (17/01/ 2001) que estableció la realización de 25,000 acciones de vivienda en 2001 (10 mil de nueva edificación en las cuatro delegaciones centrales y el resto de mejoramiento en las demás delegaciones). Posteriormente las metas se incrementaron a $150 \mathrm{mil}$ acciones para el periodo 2001-2006.

La construcción de vivienda pública ha estado a cargo del Instituto de Vivienda del Distrito Federal (Invi) a través de dos grandes programas con algunas variantes: construcción de vivienda en conjunto y mejoramiento de vivienda. En el marco del primer programa -ante las dificultades de acceso a un suelo encarecido (por la política restrictiva del Bando 2) y como consecuencia del derrumbe de un inmueble en pésimo estado físico en una colonia del centro-, en 2003 se inició el Programa Emergente de Vivienda para familias que habitan en inmuebles en alto riesgo. Así, se desplazó la construcción de vivienda nueva en baldíos o la sustitución de inmuebles abandonados, de mucho interés para los desarrolladores inmobiliarios, hacia las construcciones habitadas (y deterioradas) que difícilmente importan al sector privado.

Vivienda producida por el Gobierno del Distrito Federal: hasta septiembre de 2006 el Invi había realizado 142,660 acciones para vivienda: 69,896 construcciones nuevas y 72,764 en aspectos de mejoramiento y ampliación de vivienda. A través del Programa Vivienda en Conjunto, hasta junio de 2006 se habían llevado a cabo en la ciudad central 16,650 acciones de vivienda y en el Centro Histórico 3,364 en 110 frentes de obra (Seduvi, 2006, Anexo 9) (imagen I).

\subsection{La nueva recuperación del Centro Histórico}

El Centro Histórico de la ciudad de México se creó mediante decreto presidencial en abril de 1980 bajo la figura de Zona de Monumentos con 9.1 kilómetros cuadrados. Este territorio, que a mediados del siglo XIX más o menos constituía toda la ciudad, 


\section{Imagen I}

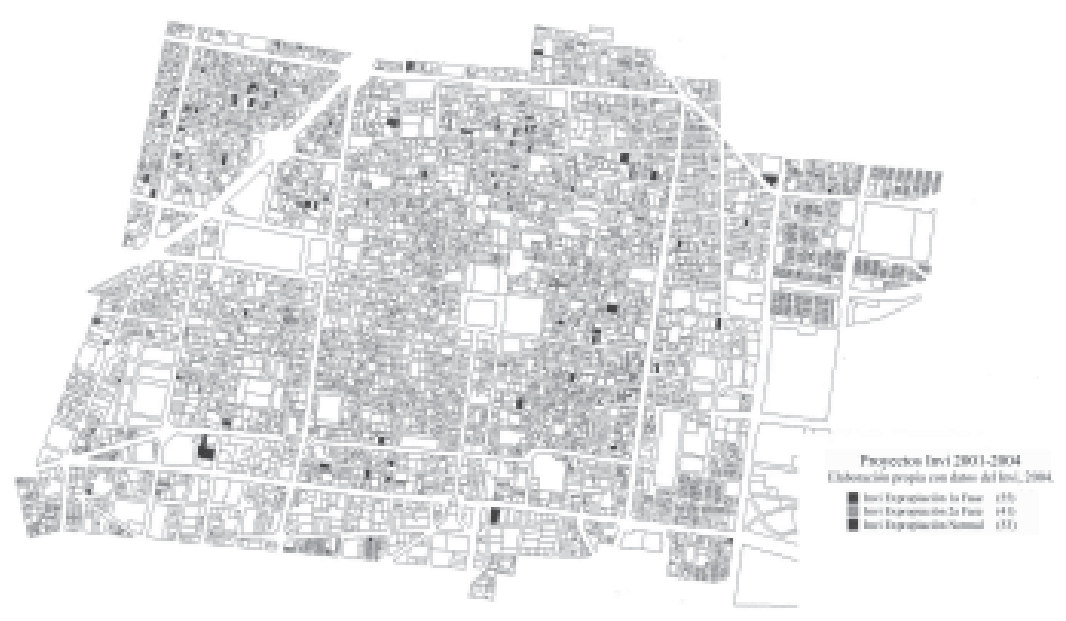

en el año 2000 alojaba 1.9\% de la población del D. F. y representaba $1.4 \%$ de su superficie urbana $(0.8 \%$ de la población y $0.5 \%$ de la superficie de la Zona Metropolitana del Valle de México). Sin embargo, funcional y simbólicamente este territorio cumple una función que rebasa con mucho su superficie y la de la capital de la nación.

El Centro Histórico mantiene su vitalidad y función de centro metropolitano a pesar del surgimiento de nuevas centralidades y del deterioro de algunos de sus barrios. En efecto, hoy día este pequeño territorio de la ciudad constituye la mayor concentración de actividades comerciales (formales e informales), administrativas, culturales y de servicios, así como la mayor densidad de monumentos históricos y artísticos del país. Es el territorio más accesible de la zona metropolitana (la red de transporte público y en parte la red vial se dirigen a él o lo atraviesan), por lo que atrae multitudes. Ésta es una de las razones principales para la presencia del comercio informal, que a su vez atrae a consumidores de bajos ingresos.

Ningún centro histórico mexicano ha sido tan rescatado como el de la ciudad de México. Desde fines de la década de 1960 este territorio ha sido objeto de cíclicos programas de recuperación y mejoramiento, ${ }^{9}$ entre los que destacan: la Remodelación de los

${ }^{9}$ Para una descripción y análisis de estos programas de rescate del Centro Histórico, véase Delgadillo, 2005. 
Centros Cívicos (1967); la Remodelación del antiguo centro comercial de la ciudad de México (1972); la Restauración de la Zona de Monumentos del Centro Histórico (1978-1982), programa que de forma excepcional remozó algunas calles al oriente de Palacio Nacional; iÉchame una manita! (1991-1994), programa que actuó en 10\% de ese territorio; el Programa para el Desarrollo Integral del Centro Histórico (1997-2000), elaborado e impulsado durante la gestión cardenista (se trata más de un ejercicio de planeación participativa y de un plan de gestión que de obra); y el Programa de rescate del Centro Histórico (20022006), realizado durante la gestión de López Obrador. Este último actúa en el mismo territorio rescatado una década atrás por el presidente Salinas de Gortari, cuenta con el mismo tipo de proyectos (remozamiento de fachadas y sustitución de mobiliario urbano), igual reubica el comercio ambulante pero moderniza la infraestructura e introduce fibra óptica y un sistema de seguridad basado en las recomendaciones del ex alcalde (del Partido Republicano) de Nueva York, además de que se construye la Plaza Juárez frente al jardín público La Alameda.

Los tres últimos programas se han realizado a través del Fideicomiso Centro Histórico (creado como entidad público-privada en 1991 y estatizado en 2002) y los tres han apostado por involucrar al sector privado a partir de la realización de obra pública y de la introducción de incentivos fiscales.

El último programa de recuperación del Centro Histórico constituye un acto de voluntad politica por parte de quien no quería hacer obras de relumbrón en el centro de la ciudad (como remodelar el Zócalo a un costo de 150 millones de pesos), ${ }^{10}$ mientras hacia falta agua en la ciudad. Sin embargo, el jefe de gobierno cambió de opinión una vez que el inversionista más rico de México y América Latina mostró interés en invertir y recuperar esa zona patrimonio de la humanidad. Así, en agosto de 2001 los gobiernos federal y local instalaron un Consejo Consultivo para el Rescate del Centro Histórico integrado por 125 personas (intelectuales, inversionistas, artistas, etc.) y un Comité Ejecutivo de dicho consejo integrado por tres ministros del gobierno federal (Cultura, Turismo y Hacienda), tres Secretarías del gobierno local (Desarrollo Urbano, Turismo y Desarrollo Económico) y cuatro representantes de la sociedad civil: un periodista, un his-

${ }^{10}$ Se trata de un concurso público convocado por el Ing. Cuauhtémoc Cárdenas, primer Jefe de Gobierno electo en la historia del D. F., que pretendía recibir el año 2000 con el ombligo del país (plaza mayor) embellecido. 
toriador, el arzobispo de la Iglesia católica y el inversionista más rico del país. Éste último preside además el Consejo Consultivo que a nadie consulta (sólo se reunió una vez, el día de su instalación) y donde están ausentes representantes de la población residente y de los comerciantes de ese territorio.

El GDF estatizó el Fideicomiso Centro Histórico en febrero de 2002, institución a la que encomendó recuperar el núcleo urbano, un territorio de 34 manzanas que representan 5\% del Centro Histórico, y destinó una inversión pública a fondo perdido por un monto de 500 millones de pesos para la realización de obra pública (que es como algunos gobernantes conciben la acción de un buen gobierno). Así, se mejoró una vez más un territorio mejorado una década atrás: se remozó el espacio público, se sustituyeron pavimentos, banquetas y mobiliario urbano, se remozaron fachadas, se modernizó la infraestructura y de nueva cuenta se reubicó a los vendedores ambulantes en las zonas remodeladas.

Por su parte, el señor Slim, presidente del Consejo Consultivo, adquirió una serie de inmuebles y se benefició de importantes exenciones fiscales locales y federales, que parecen hechas ex profeso para este nuevo defensor del patrimonio urbano arquitectónico. Entre abril de 2002 y mayo de 2004 adquirió 63 inmuebles a través de una sociedad mercantil denominada Centro Histórico de la Ciudad de México, S. A. de C. V., o de otras de sus empresas (Telmex, Inbursa, Carso) (imagen II). La mayor parte de estos inmuebles se ubican al sur del distrito de negocios y frente al Palacio de Bellas Artes. Evidentemente no se privatiza el Centro Histórico, un territorio integrado por poco más de 9,200 predios.

¿La inversión pública detona la inversión privada o viceversa? El GDF constantemente señala que gracias a la inversión pública se ha detonado una gran inversión privada. De acuerdo con el GDF (ALDF, 2003), entre 2001 y 2003 se consiguió una inversión privada de 5 mil millones de pesos en el Centro Histórico, sin embargo, una lectura detenida de los hechos permite afirmar lo contrario: la inversión privada detonó la inversión pública. Todo indica que la inversión privada en el Centro Histórico se hubiera realizado de igual modo y sin necesidad de un programa público de rescate: 1) el señor Slim ya había anunciado en agosto de 2001 que invertiría mil millones de pesos para rescatar la zona, mientras que el GDF hizo del conocimiento público una inversión de 500 millones de pesos para rescatar el Centro Histórico hasta febrero de 2002; 2) algunos desarrolladores inmobiliarios que 


\section{Imagen II}

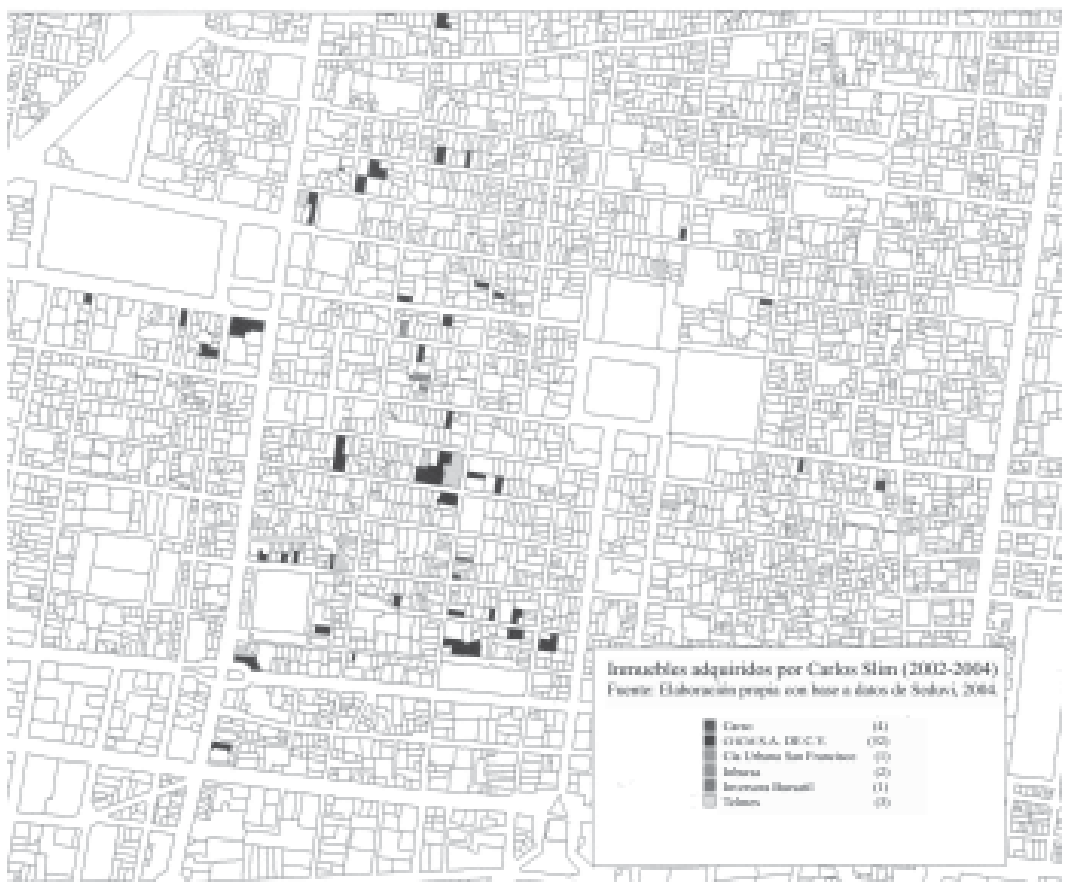

invierten en la zona lo hacían desde antes del año 2000 y a partir del 2001 construyen vivienda nueva en partes periféricas del Centro Histórico, más por la influencia de la política de desarrollo urbano (Bando 2) que por el rescate del centro. A ellos no les interesa el patrimonio ni la rehabilitación de inmuebles, su negocio es la construcción de vivienda nueva sobre lotes baldíos o en sustitución de inmuebles.

\subsection{Vivienda y patrimonio, una acción pública híbrida}

Como se señaló en el apartado anterior, en el Centro Histórico se llevaron a cabo un número importante de acciones habitacionales entre 2000 y 2006, sin embargo, se trata de obras que en estricto sentido nada tienen que ver con el programa de recuperación de este territorio. Son dos políticas sectoriales que actúan con lógicas diferentes, se dirigen a población distinta en dos zonas diferentes del mismo territorio denominado Centro Histórico; es decir, se trata de una gestión doble, simultánea e híbrida.

Entre 2001 y 2006 el Invi realizó en el centro histórico 3,364 acciones habitacionales (construcción nueva, rehabilitación o 
compraventa) y el sector privado 3,885 . Se trata de una contribución importante para evitar el despoblamiento y mantener la función habitacional de la zona, sin embargo, son acciones viviendistas dispersas en las zonas oriente, norte y sur del centro histórico que se caracterizan por el deterioro del espacio público y la obsolescencia de la infraestructura. Salvo contadas excepciones, no coinciden con el territorio donde actúa el programa de rescate del Centro Histórico. Estas acciones no se acompañan de la mejora del espacio público y de la infraestructura, no hay ordenamiento territorial, no se enfrentan presiones terciarias ni el problema de los vendedores ambulantes y no hay medidas que mejoren la seguridad pública. Además, la inversión en vivienda de interés social es en parte recuperable, pues se trata del otorgamiento de créditos para el acceso a una vivienda en propiedad.

En el otro territorio constituido por 34 manzanas, el programa de rescate del Centro Histórico no sólo revalora la propiedad privada a través de la mejora del espacio público y el remozamiento de las fachadas, sino que se reubican las actividades consideradas dañinas para la imagen urbana y la dignidad del patrimonio (el comercio ambulante y la celebración de los Reyes Magos en La Alameda), se fortalece la seguridad pública y la inversión pública se realiza a fondo perdido. Además, la plusvalía que genera la acción no se recupera, merced a los incentivos fiscales que facilitan los negocios privados.

Así, todo indica que el último programa de rescate del centro histórico es una reedición corregida y aumentada del programa realizado por la gestión salinista de la ciudad, donde se combina el beneficio de los sectores privado y público: el primero hace negocios inmobiliarios al amparo de incentivos públicos y los propietarios revaloran sus edificios a partir de las obras de remozamiento que gratuitamente realiza el gobierno local; mientras que el segundo obtiene beneficios políticos y demuestra que un gobierno de izquierda puede trabajar con la iniciativa privada.

\section{Los resultados de la política de repoblamiento}

Contrario a las buenas cuentas del gobierno local, los últimos datos oficiales demuestran que los trabajos de construcción de vivienda pública y privada no han conseguido repoblar masivamente la ciudad central, es decir, que construir vivienda no garantiza el repoblamiento. Veamos. 
El Distrito Federal es una entidad que desde la década de 1980 casi no crece. Esta relativa estabilidad demográfica en realidad es la incapacidad de una ciudad encarecida por retener a su población y ofrecer opciones accesibles de alojamiento a la población de bajos ingresos. Además, aunque en los últimos 25 años el D. F. mantiene casi la misma población y densidad de habitantes, en los municipios conurbados éstas se han incrementado. Es decir, la ciudad real crece.

De acuerdo con datos del INEGI (2006), en el periodo 20002005 el saldo neto de crecimiento poblacional del D. F. fue un incremento de 115.6 mil habitantes. Sin embargo, al interior del territorio ocurren diversos fenómenos.

- Seis delegaciones siguen perdiendo población $(107,555$ habitantes en total): Azcapotzalco, Coyoacán, Gustavo A. Madero, Iztacalco, Benito Juárez y Venustiano Carranza (las dos últimas perdieron 5,461 y 15,347 habitantes, respectivamente)

- De las 10 delegaciones que presentan un incremento total de población de 223.2 mil nuevos habitantes, 97.3\% (217.2 mil habitantes) se realiza en ocho delegaciones con suelo de conservación ecológico, las cuales son objeto de una política restrictiva de desarrollo urbano: Álvaro Obregón, Cuajimalpa, Iztapalapa, Magdalena Contreras, Milpa Alta, Tláhuac, Tlalpan y Xochimilco.

- Sólo en dos delegaciones (Cuauhtémoc y Miguel Hidalgo) se consiguió revertir el despoblamiento con un respectivo saldo positivo de 5,093 y de 894 habitantes.

Por su parte, el proceso de despoblamiento de la llamada ciudad central corresponde con un proceso de pérdida de vivienda entre 1980 y 2000 , que se desaceleró entre 1995 y 2000 y se revirtió en el periodo 2000-2005. Así, en los últimos 15 años la vivienda ha crecido a un ritmo casi cinco veces mayor que la población, y en el último quinquenio lo hizo a un ritmo de 6.5 veces. Además del boom inmobiliario, este hecho se explica porque las familias tienden a integrarse con menos miembros.

De acuerdo con datos oficiales (INEGI, 2006), en el último quinquenio se contabiliza un incremento neto de 183,437 viviendas: la mitad se edificó en cinco demarcaciones restringidas en la cons- 
trucción de conjuntos habitacionales. ${ }^{11}$ Por su parte, en las cuatro delegaciones centrales, donde se concentraron los esfuerzos de construcción de vivienda con recursos públicos y privados, apenas se registra la quinta parte del incremento habitacional del quinquenio con un saldo neto de 36,214 viviendas (Benito Juárez 8,435 viviendas, Cuauhtémoc 13,128, Miguel Hidalgo 11,530 y Venustiano Carranza 3,121). Aquí se consiguió detener la tendencia de pérdida de viviendas.

\section{Comentarios finales}

En los programas de gobierno que se realizan en el Centro Histórico no aparece estrategia alguna de planificación, sino dos formas de actuación dirigidas a diferentes actores y territorios sin vínculos: por un lado inversiones millonarias a fondo perdido para remozar un pequeño territorio y, por otro, inversiones públicas recuperables (créditos) y subsidios destinados a atender algunas vecindades en riesgo de derrumbe donde habita población de bajos ingresos. Ambos tipos de intervención no tienen vínculos entre sí y no se complementan: la inversión públicoprivada en el distrito de negocios, al margen de generar un impacto positivo en esa zona (en términos de recuperación del espacio subutilizado y de una posible reinversión), no genera ningún beneficio en la zona tugurizada del centro; mientras que las acciones viviendistas dispersas en la otra parte del territorio difícilmente pueden revertir por sí solas el deterioro edilicio y social, así como la pujante actividad del comercio informal que invade la vía pública y ocupa los edificios como almacenes. En los hechos directamente se subsidia mucho más a unos cuantos inversionistas que a las familias de bajos ingresos que deben pagar los créditos recibidos. Además, estas políticas no están exentas de contradicciones: revalorizan el mercado inmobiliario y las propiedades privadas e implican el alza de las rentas urbanas, lo que imposibilita la permanencia en ellas de los actores sociales de más bajos ingresos.

Las acciones habitacionales realizadas constituyen una gran contribución para intentar revertir los procesos de despilfarro y despoblamiento de la ciudad central y para frenar la depreda-

${ }^{11}$ No deduzco que se trata de la construcción masiva de vivienda, puede tratarse de edificaciones aisladas y dispersas o del programa de mejoramiento de vivienda, realizado por el Invi, que en varios casos construye nuevas viviendas en sitios donde ya existe una. 
ción del medio ambiente en las periferias urbanas, pero aún son insuficientes.

De acuerdo con los datos estadísticos más recientes, en la ciudad de México no hay una correspondencia directa entre la construcción de vivienda y la reversión de las tendencias de despoblamiento. Es decir, construir viviendas no garantiza el retorno o la permanencia de población. Aquí se apuntan una serie de causas que pueden influir en este complejo fenómeno del despoblamiento en un contexto de producción de viviendas: 1) las acciones habitacionales son mucho menores que la dinámica de expulsión de la población, 2) las viviendas, entre ellas algunas recientemente construidas, se destinan a usos más rentables (comercios, almacenes u oficinas) ${ }^{12}$ y 3) la producción de vivienda, particularmente la que se destina a la población de mayores ingresos, implica el desplazamiento de más pobladores que los que beneficia.

Finalmente, recuperar y repoblar un territorio requiere, por un lado, de un conjunto de políticas sociales y económicas que reconstituyan el tejido social, eleven el nivel de vida de la población residente (a través de programas de capacitación y del acceso a empleos mejor remunerados) y por otro, de acciones de mejoramiento de los barrios que acompañen las acciones habitacionales, como la recuperación del espacio público, el ordenamiento de las actividades, el control de las presiones terciarias y en su caso de la reubicación del comercio ambulante, la mejora de la infraestructura, la generación de equipamientos del barrio, etc. Es decir, el retorno al centro, además de voluntad política requiere de un conjunto de políticas sociales y económicas definidas en el marco de un proyecto consensado de ciudad.

${ }^{12}$ En el caso de algunas vecindades rehabilitadas recientemente por el Invi, he constatado el rápido cambio de uso del suelo por comercios o servicios. Aquí la crítica no radica en que una vivienda se destine a otra actividad que así le convenga a las familias residentes, sino a la política habitacional que otorga considerables subsidios al remozamiento de inmuebles que tal vez no los requieren, porque las actividades a las que se destinan pueden pagar los costos de rehabilitación. 


\section{Bibliografía}

ALDF (Asamblea Legislativa del Distrito Federal) (2003), Decreto por el que se aprueba el Programa General de Desarrollo Urbano del Distrito Federal, Gaceta Oficial del D. F., México, 31 de diciembre de 2003.

Amendola, Giandomenico (2000), La ciudad postmoderna, Madrid, España, Celeste.

Aravena, Bernabé (2005), "Programa de Repoblamiento de la Corporación para el Desarrollo de Santiago de Chile", ponencia presentada en el Encuentro Taller Iberoamericano Vivienda en la Ciudad Central, organizado por el GDF, la UNAM y el programa CYTED en la ciudad de México, febrero de 2005, inédito.

Balbó, Marcelo (2003), "La nueva gestión urbana”, en Ricardo Jordán y Gabriela Simioni (comps.), Gestión urbana para el desarrollo sostenible en América Latina y el Caribe, CEPAL-Gobierno de Italia, Santiago de Chile, pp. 71-93.

Batley, Richard (1998), "Nuevas direcciones en política y gestión urbana", en Eduardo Rojas y Robert Daughters (eds.), La ciudad en el siglo XXI, experiencias exitosas en gestión del desarrollo urbano en América Latina, Banco Interamericano de Desarrollo, Washington, Estados Unidos, pp. 13-19.

Carrión, Fernando (ed.) (2001), La ciudad construida, urbanismo en América Latina, FLACSO Ecuador-Junta de Andalucía, Quito, Ecuador.

Castillo Juárez, Laura Itzel (2005), "Regreso a la ciudad central”, ponencia presentada en el v Seminario Internacional de Suelo Urbano. Redensificación de la Ciudad Central a Debate, organizado por el PUEC, la UNAM y el Lincoln Police Institute, ciudad de México, 29 y 30 de septiembre de 2005, inédito.

Delgadillo, Víctor (2005), “Centros Históricos de América Latina, riqueza patrimonial y pobreza social: la rehabilitación de vivienda en Buenos Aires, ciudad de México y Quito 
en el periodo 1990-2003", tesis doctoral en urbanismo, UNAM, inédito.

FCH (Fideicomiso Centro Histórico) (2001), "Propuesta de programa de regeneración habitacional para el Centro Histórico de la ciudad de México 2002-2006”, elaborado por René Coulomb y Víctor Delgadillo, inédito.

García Vázquez, Carlos (2004), Ciudad hojaldre, visiones urbanas del siglo XXI, Gustavo Gili, Barcelona, España.

Herzog, Lawrence A. (2006), Return to the Center: Culture, Public Space and City Building in a Global Era, University of Texas Press, Texas, Estados Unidos.

INEGI (Instituto Nacional de Estadística, Geografía e Informática) (2006), Resultados del Conteo Nacional de Población y Vivienda 2005, en www.inegi.gob.mx, 13 de enero de 2007.

Jordán, Ricardo (2003), “Ciudad y desarrollo en América Latina y el Caribe", en Ricardo Jordán y Gabriela Simioni (comps.), Gestión urbana para el desarrollo sostenible en América Latina y el Caribe, CEPAL-Gobierno de Italia, Santiago de Chile, pp. 43-70.

Lattes, Alfredo E. (2001), "Población urbana y urbanización en América Latina", en Fernando Carrión (ed.), La ciudad construida, urbanismo en América Latina, FLACso EcuadorJunta de Andalucía, Quito, Ecuador, pp. 49-76.

Mercado, Ángel (1997), Proyecto Centro Histórico Ciudad de México. Informe final, ARDF, México.

Melé, Patrice (1998), Patrimoine et action publique au centre des Villes Mexicaines, Creedla-Éditions de l'IHEAL, París, Francia.

Morteo Báez, José Alfredo (2005), “La acción del Infonavit en la Zona Metropolitana de la Ciudad de México", ponencia presentada en el Encuentro Taller Iberoamericano Vivienda en la Ciudad Central, organizado por el GDF, la UNAM y el programa CYTED en la ciudad de México, febrero de 2005, inédita. 
Nintied, Peter (1998), "La ciudad como motor del desarrollo: necesidad de una visión estratégica", en Eduardo Rojas y Robert Daughters (eds.), La ciudad en el siglo XXI, experiencias exitosas en gestión del desarrollo urbano en América Latina, Banco Interamericano de Desarrollo, Washington, Estados Unidos, pp. 33-41.

PAOT (Procuraduría Ambiental y del Ordenamiento Territorial del D. F.) (2006), Usos de suelo urbano e impactos de la densificación en la ciudad de México, Documento de trabajo, México, inédito.

Rojas, Eduardo, Eduardo Rodríguez y Emiel Wegelin (2004), Volver al centro, la recuperación de áreas urbanas centrales, Banco Interamericano de Desarrollo, Washington, Estados Unidos.

Sassen, Saskia (1997), Metropolen des Weltmarkts, die neue Rolle del Global Cities, Campus Verlag, Frankfurt am Main.

Seduvi (Secretaría de Desarrollo Urbano y Vivienda) (2006), Sexto Informe de Trabajo, Gobierno del Distrito Federal, septiembre, México.

Tamayo, Sergio (2001), "Archipiélagos de la modernidad urbana, arquitecturas de la globalización en la ciudad de México", en Anuario de espacios urbanos 2001, Universidad Autónoma Metropolitana-Azcapotzalco, México, pp. 187-233.

Tung, Anthony M. (2002), Preserving the World's Great Cities: The Destruction and Renewal of the Historic Metropolis, Three Rivers Press, Nueva York, Estados Unidos.

uN Habitat (United Nations Human Settlements Programme) (2003), The Challenge of Slums, Global Report on Human Settlements 2003, uN Habitat-Earthscan Publications, London-Sterling, VA.

Wentz, Martin (2000), Die Kompakte Stadt, Campus Verlag, Frankfurt am Main. 
Recibido: 1 de marzo de 2007. Aceptado: 6 de septiembre de 2007.

Víctor Manuel Delgadillo-Polanco. Es maestro en arquitectura y planeación urbana por la Universidad de Stuttgart (1993) y doctor en urbanismo por la Universidad Nacional Autónoma de México (2005). Fue consultor de la UNESCO para la elaboración del Programa de Ordenamiento Urbano Ambiental y Plan de Gestión para la recuperación del patrimonio cultural y natural de Xochimilco, entre 2005 y 2006, y actualmente es profesor de tiempo completo en el Colegio de Humanidades y Ciencias Sociales de la Universidad Autónoma de la Ciudad de México, Plantel San Lorenzo Tezonco. Su línea de investigación actual se centra en urbanismo y patrimonio cultural en América Latina: actores sociales y políticas públicas; políticas de reciclamiento y desarrollo urbano, así como vivienda en áreas urbanas centrales. Entres sus últimas publicaciones destacan: en coautoría con Ciro Caraballo y Yadira Correa, "Planeación territorial y dinámica urbana, fuerzas en choque continuo. Políticas de ordenamiento territorial y conservación ambiental en Xochimilco", en Ciro Caraballo (coord.), Xochimilco, un proceso de gestión participativa, UNESCO-GDF-Delegación Xochimilco, México, 2006, pp. 231237; "Rehabilitación urbana, vivienda y exclusión social en los centros históricos de América Latina”, en Fernando Greene (coord.), Urbanismo y vivienda, UNAM, México, 2005, pp. 181-194; "Die peripherie im Zentrum, die Rehabilitierung der Altstädte führt zu neuem sozialen Ausschluss", Lateinamerika Nachrichten, Berlín, 2004, pp. 37-41; "Housing Rehabilitation in Mexico City's Historical Downtown", revista electrónica del Programa de Intercambio Sur-Sur para la Investigación en la Historia del Desarrollo del Instituto de Historia Social de los Países Bajos, SEPHIS, en www.sephis.org/htm/papers/htm, 2003. 